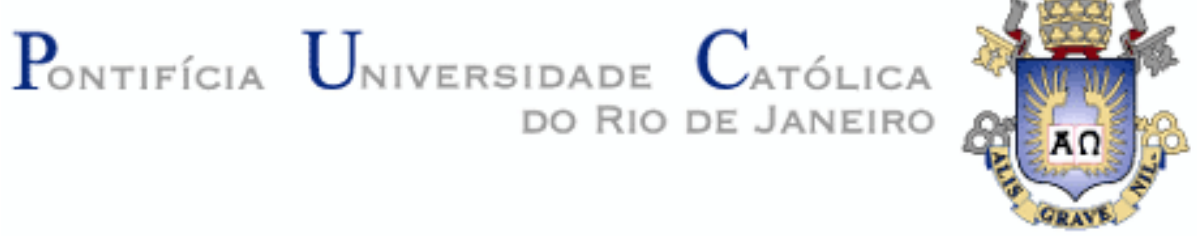

Paulo Marcelo de Miranda Serrano

\begin{abstract}
CAMINHOS PARA A CORTE:
Estado e sociedade na escolha dos ministros do Supremo Tribunal Federal
\end{abstract}

Tese de Doutorado

Tese apresentada como requisito parcial para obtenção de grau de doutor pelo Programa de Pós-Graduação em Ciências Sociais da Pontifícia Universidade Católica do Rio de Janeiro.

Orientador: Prof. Eduardo de Vasconcelos Raposo

Rio de Janeiro

Fevereiro de 2015 


\section{CAMINHOS PARA A CORTE: \\ Estado e sociedade na escolha dos ministros do Supremo Tribunal Federal}

Tese apresentada como requisito parcial para obtenção do grau de Doutor pelo Programa de PósGraduação em Ciências Sociais do Departamento de Ciências Sociais do Centro de Ciências Sociais da PUC-Rio. Aprovada pela Comissão Examinadora abaixo assinada.

Prof. Eduardo de Vasconcelos Raposo Orientador

Departamento de Ciências Sociais/PUC-Rio

Profa. Maria Tereza Aina Sadek

USP

Prof. Aurélio Wander Chaves Bastos UNIRIO

Profa. Maria Alice Rezende de Carvalho Departamento de Ciências Sociais/PUC-Rio

Prof. Luiz Jorge Werneck Vianna Departamento de Ciências Sociais/PUC-Rio

Profa. Mônica Herz Coordenadora Setorial do Centro de Ciências Sociais - PUC-Rio

Rio de Janeiro, 10 de fevereiro de 2015 
Todos os direitos reservados. É proibida a reprodução total ou parcial do trabalho sem autorização da universidade, do autor e do orientador.

\section{Paulo Marcelo de Miranda Serrano}

Graduou-se em Direito pela Universidade Candido Mendes (1987). Possui mestrado em Direito Comparado pela University of Miami School of Law (1998) e mestrado em Ciências Sociais pela PUC-Rio (2010). Professor do Departamento de Direito da PUCRio e desembargador do Tribunal Regional do Trabalho da $1^{a}$ Região. Tem interesses em Ciências Sociais e Direito.

Ficha Catalográfica

Serrano, Paulo Marcelo de Miranda

Caminhos para a corte: estado e sociedade na escolha dos ministros do Supremo Tribunal Federal / Paulo Marcelo de Miranda Serrano ; orientador: Eduardo de Vasconcelos Raposo. - 2015. 2938 f. : il. (color.) ; $30 \mathrm{~cm}$

Tese (doutorado)-Pontifícia Universidade Católica do Rio de Janeiro, Departamento de Ciências Sociais, 2015.

Inclui bibliografia

1. Ciências Sociais - Teses. 2. Supremo Tribunal Federal. 3. Ministros. 4. Escolha. 5. Modelo. 6. Estado. 7. Sociedade. I. Raposo, Eduardo de Vasconcelos II. Pontifícia Universidade Católica do Rio de Janeiro. Departamento de Ciências Sociais. III. Título. 


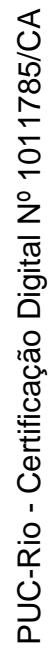

Para Mariah.

Para Marcela, Guilherme e Bernardo.

Para Patrícia. 


\section{Agradecimentos}

Ao meu professor orientador Eduardo de Vasconcelos Raposo.

Aos professores que participaram da Banca Examinadora, Maria Tereza Aina Sadek, Maria Alice Rezende de Carvalho, Luiz Werneck Vianna e Aurélio Wander Bastos.

Ao corpo docente do Departamento de Ciências Sociais, pelo estimulante ambiente.

Aos entrevistados, pela generosidade.

À Biblioteca do Senado Federal, na pessoa de Maria Neves de Oliveira e Silva, diretora da Subsecretaria de Pesquisa e Recuperação de Informações Bibliográficas, pela incansável contribuição.

À Biblioteca Ministro Victor Nunes Leal, do Supremo Tribunal Federal.

À Biblioteca da Fundação Casa de Rui Barbosa.

À Biblioteca do Tribunal Regional do Trabalho da $1^{\mathrm{a}}$ Região.

À Biblioteca da PUC-Rio. 


\section{Resumo}

Serrano, Paulo Marcelo de Miranda; Raposo, Eduardo de Vasconcelos. Caminhos para a Corte: Estado e sociedade na escolha dos ministros do Supremo Tribunal Federal. Rio de Janeiro, 2015. 2938p. Tese de Doutorado. Departamento de Ciências Sociais. Pontifícia Universidade Católica do Rio de Janeiro.

O tema da pesquisa é o Supremo Tribunal Federal, enfrentando a seguinte questão: o modelo de escolha dos ministros do STF deve ser alterado ou mantido? A investigação tem por objetivo chaves para essa indagação. A relevância do tema é justificada pela importância, no cenário nacional, do Supremo Tribunal Federal, que, além de se encontrar no vértice do Poder Judiciário, encontra-se presente, de forma crescente, na vida contemporânea da sociedade brasileira. São objetivos intermediários da pesquisa: verificar por que o Senado brasileiro, nos séculos 20 e 21, até o momento, jamais deixou de aprovar a escolha dos presidentes da República; quem são os ministros do período mais recente, adotando-se como delimitação temporal os trintas anos do período de redemocratização iniciados em 1985; e, finalmente, por que o Brasil mudou tanto desde 1891 e a forma de escolha dos ministros do STF nunca foi alterada, bem como de que maneira o aparente paradoxo existente entre um sistema institucional dinâmico e um modelo de escolha conservador pode nos revelar o caráter do sistema institucional brasileiro. Ao final, respondendo ao objetivo geral, avalia-se quais são as alterações com maior viabilidade de serem introduzidas, tanto por cambio formal do modelo, quanto pelo modo de sua efetivação e acompanhamento pela sociedade. A seguir, é feita contribuição própria, apontando caminhos para ensejar e motivar a participação da sociedade civil no processo. Encerrando o trabalho, após desvendar os caminhos que levam homens e mulheres para a Corte Suprema brasileira, que, por sua vez, determinam os caminhos que a própria Corte percorrerá, é feito, em considerações finais, um esforço interpretativo que sugere o que pode a escolha dos ministros do Supremo Tribunal Federal, enquanto fenômeno sócio-político, revelar sobre o Brasil contemporâneo.

\section{Palavras-chave}

Supremo Tribunal Federal; ministros; escolha; modelo; Estado; sociedade. 


\section{Abstract}

Serrano, Paulo Marcelo de Miranda; Raposo, Eduardo de Vasconcelos. (Advisor) Paths to the Court: State and society in the nomination of justices to the Brazilian Supreme Court. Rio de Janeiro, 2015. 2938p. PhD's Thesis. Department of Social Sciences. Pontifícia Universidade Católica do Rio de Janeiro.

The research theme is the Brazilian Supreme Court, facing the following question: should the model of choosing the justices be altered or maintained? The goal of the investigation is finding keys to this question. The relevance of the theme is justified by the importance, in the national scene, of the Brazilian Supreme Court, which not only is at the top of the Judiciary Power, but finds itself increasingly present in contemporary brazilian society life. Intermediate goals of the research are: investigate why the brazilian Senate, from the 20th and 21st century until present day, has never disapproved the choice of presidents of the Republic; who are the most recent ministers, setting as temporal delimitation the thirty years of redemocratization starting in 1985; and finally, why did Brazil change so much since 1891 and the model of choosing justices was never altered, as well as how the apparently existing paradox between an institutional dynamic system and a conservative model of choice can reveal the character of the Brazilian institutional system. In closing, while answering the main goals, an review on the alterations with most viability of being introduced in provided, both by formal model switching as well as by method of execution and followup by society. After that, a personal contribution is made, pointing paths to give rise and motivate participation of the civil society in this process. Finishing the research, after unveiling the paths that lead men and women to the Brazilian Supreme Court, paths that determine the course of the Court itself, an effort is made, as final considerations, suggesting what the choice of ministers of the Brazilian Supreme Court, as a social-political phenomena, reveal about contemporary Brazil.

\section{Keywords}

Brazilian Supreme Court; Justices; Appointment; Model; State; society. 


\section{Sumário}

1. Introdução

2. A escolha dos ministros do STF 36

2.1. Antecedentes históricos 36

2.1.1. Supremo Tribunal de Justiça 37

2.1.2. Constituição dos EUA e sua repercussão no Brasil 38

2.1.3. Constituição Republicana de 1891

2.1.4. Supremo Tribunal Federal 42

2.1.5. Influência do sistema e instituições dos EUA no Supremo
Tribunal Federal

2.2. Modelo brasileiro 49

2.2.1. A escolha dos ministros 50

2.2.2. A escolha do presidente do STF 51

2.2.3. As nomeações e alguns problemas na história 53

3. Modelos do direito comparado

3.1. Cortes Supremas $\quad 57$

3.1.1. Estados Unidos da América 57

3.1.1.1. A escolha dos juízes da Suprema Corte 58

3.1.1.2. A escolha do presidente da Suprema Corte 59

3.1.1.3. Nomeações de recesso 60

3.1.1.4. Considerações sobre o funcionamento do modelo na prática 61

3.1.2. América Latina 64

3.1.2.1. Argentina 64

3.1.2.2. Venezuela 65

3.1.2.3. Colômbia 66

$\begin{array}{ll}\text { 3.1.2.4. Bolívia } & 67\end{array}$

$\begin{array}{ll}\text { 3.1.2.5. México } & 68\end{array}$ 
3.1.3. Quadro comparativo das Cortes Supremas 69

3.2. Cortes Constitucionais 71

3.2.1. Europa Continental 71

3.2.1.1. Áustria 71

3.2.1.2. Alemanha 73

3.2.1.3. Itália 74

3.2.1.4. França 75

3.2.1.5. Portugal 77

3.2.1.6. Espanha 78

3.2.2. América Latina 78

3.2.2.1. Chile 79

3.2.2.2. Equador $\quad 80$

$\begin{array}{ll}\text { 3.2.2.3. Peru } & 81\end{array}$

3.2.2.4. Uruguai 82

3.2.2.5. Paraguai 82

3.2.3. Quadro comparativo das Cortes Constitucionais 84

4. Análise do modelo vigente 88

4.1. Pela adoção de novo modelo 88

4.1.1. Críticas relativas ao órgão político que faz a indicação 89

4.1.1.1. Preponderância do Executivo e déficit democrático 90

4.1.1.2. Possível comprometimento da imparcialidade do futuro
ministro

4.1.1.3. Possibilidade de um mesmo presidente indicar expressivo
número de ministros

4.1.1.4. Critérios subjetivos na escolha do candidato a ser nomeado 113

4.1.1.5. Amizade com presidente e políticos pode ser determinante na indicação 115

4.1.1.6. Indicação política 116

4.1.1.7. Inexistência de prazo para escolha do futuro ministro 117 
4.1.2. Críticas quanto ao órgão político que aprova (ou não) as escolhas 121

4.1.2.1. O Senado Federal sempre aprova os indicados pelo presidente da República

4.1.3. Críticas relativas ao procedimento de aprovação 122

4.1.3.1. Quorum para aprovação no Senado 122

4.1.3.2. Aprovação apenas por uma das Casas do Congresso Nacional 125

4.1.3.3. Impossibilidade do Senado periodicamente decidir pela manutenção ou não do ministro nomeado 126

4.1.4. Críticas relativas aos requisitos dos candidatos 129

4.1.4.1. Idade mínima e/ou máxima 129

4.1.4.2. Ausência de quarentena anterior 135

4.1.4.3. Inexigência de bacharelado em Direito 137

4.1.4.4. Tempo de atividade jurídica 139

4.1.4.5. Inexistência de vagas destinadas a ministros de Tribunais Superiores, desembargadores e juízes

4.1.4.6. Inexistência de vedação ao candidato com condenação criminal em qualquer instância

4.1.5. Críticas relativas à vitaliciedade dos ministros e ausência de vedações posteriores ao afastamento do cargo

4.1.5.1. Vitaliciedade

4.1.5.2. Ausência de quarentena posterior 155

4.1.6. Outras críticas 157

4.1.6.1. Quantidade de membros da Corte 157

4.1.6.2. Ambiguidade das expressões "reputação ilibada" e "notável saber jurídico"

4.1.6.3. Composição por membros que não são juízes togados 160

4.1.6.4. A não participação direta da sociedade 161

4.1.6.5. A não existência de concurso público 162

4.1.6.6. Pouca representação do gênero feminino na Corte 164

4.2. Pela manutenção do modelo seletivo atual 166

4.2.1. Quanto às críticas relativas ao órgão político que faz a indicação 167

4.2.1.1. Quanto à preponderância do Executivo e déficit democrático 173 
4.2.1.2. Quanto ao possível comprometimento da imparcialidade do futuro ministro

4.2.1.3. Quanto à possibilidade de um mesmo presidente indicar expressivo número de ministro

4.2.1.4. Quanto aos critérios subjetivos na escolha do candidato a ser nomeado

4.2.1.5. Quanto à amizade com presidente e políticos poder ser determinante na indicação

4.2.1.6. Quanto a ser política a indicação

4.2.1.7. Quanto à inexistência de prazo para escolha do futuro ministro

178

4.2.2. Quanto às críticas a respeito do órgão político que aprova (ou não) as escolhas

4.2.2.1. O Senado Federal sempre aprova os indicados pelo presidente da República

4.2.3. Quanto às críticas relativas ao procedimento de aprovação

4.2.3.1. Quorum para aprovação no Senado

179

4.2.3.2. Aprovação apenas por uma das Casas do Congresso Nacional

180

4.2.3.3. Impossibilidade do Senado periodicamente decidir pela manutenção ou não do ministro nomeado

4.2.4. Quanto às críticas relativas aos requisitos dos candidatos

4.2.4.1. Quanto à idade mínima e/ou máxima

4.2.4.2. Quanto à ausência de quarentena anterior

4.2.4.3. Quanto à inexigência de bacharelado em Direito

4.2.4.4. Quanto ao tempo de atividade jurídica

4.2.4.5. Quanto à inexistência de vagas destinadas a ministros de Tribunais Superiores, desembargadores e juízes

4.2.4.6. Quanto à inexistência de vedação ao candidato com condenação criminal em qualquer instância

4.2.5. Quanto às críticas relativas à vitaliciedade dos ministros e ausência de vedações posteriores ao afastamento do cargo

4.2.5.1. Quanto à vitaliciedade e ao estabelecimento de mandato

4.2.5.2. Quanto à ausência de quarentena posterior

4.2.6. Quanto às demais críticas 
4.2.6.2. Quanto à ambiguidade das expressões "reputação ilibada" e "notável saber jurídico"

4.2.6.3. Quanto à composição por membros que não são juízes togados

203

4.2.6.4. Quanto à não participação direta da sociedade 204

4.2.6.5. Quanto à não existência de concurso público 204

4.2.6.6. Quanto à pouca representação do gênero feminino na Corte 204

5. Propostas para modificação do modelo atual 205

5.1. Propostas de Emenda à Constituição com origem no Congresso Nacional

205

5.1.1. Alterações quanto ao órgão político que faz a indicação 205

5.1.1.1. Evitar a preponderância do Executivo e ampliar a participação na indicação

206

5.1.1.2. Estabelecer prazo para escolha do futuro ministro

216

5.1.2. Alterações relativas ao procedimento de aprovação pelo Senado Federal

216

5.1.2.1. Aumentar quorum para aprovação no Senado

216

5.1.2.2. Determinar aprovação pelas duas Casas do Congreso Nacional

217

5.1.2.3. Estabelecer confirmação periódica dos ministros 217

5.1.3. Alterações relativas aos requisitos dos candidatos 217

5.1.3.1. Aumentar idade mínima e/ou máxima 217

5.1.3.2. Estabelecer quarentena anterior 218

5.1.3.3. Exigir bacharelado em Direito 219

5.1.3.4. Estabelecer tempo mínimo de atividade jurídica 219

5.1.3.5. Estabelecer vagas para ministros de Tribunais Superiores, desembargadores e juízes

5.1.3.6. Estabelecer vedação para o candidato com condenação criminal em qualquer instância

5.1.4. Alterações relativas à vitaliciedade e vedações posteriores ao afastamento 
5.1.4.2. Estabelecer quarentena posterior

5.1.5. Outras alterações 221

5.1.5.1. Aumentar a quantidade de membros da Corte 221

5.1.5.2. Definir as expressões "notável saber jurídico" e "reputação ilibada"

5.1.5.3. Estabelecer composição da Corte apenas por juízes togados 222

5.1.5.4. Estabelecer o critério da eleição para escolha dos ministros 222

5.1.5.5. Estabelecer o critério do concurso público para escolha dos ministros

5.1.5.6. Estabelecer o critério de gênero para acesso

223

5.1.6. Sistematização das propostas de alteração com origem no Congresso Nacional

224

5.1.6.1. Senado Federal 224

5.1.6.2. Câmara dos Deputados 227

5.2. Outra iniciativa para alteração do modelo atual 232

5.3. Classificação das alterações propostas 233

6. Reflexões sobre o modelo e as escolhas no período atual de redemocratização

6.1. O papel do Senado na aprovação da escolha feita pelo presidente da República

238

6.2. Quem são os ministros

259

6.3. Por que o Brasil mudou tanto desde 1891 e a forma de escolha dos ministros nunca foi alterada?

7. Considerações Finais

342

8. Referências Bibliográficas 
Anexo 1 - Senado Federal - PEC 57/1995 404

Anexo 2 - Senado Federal - PEC 3/1998 414

Anexo 3 - Senado Federal - PEC 7/1999 417

Anexo 4 - Senado Federal - PEC 28/2002 438

Anexo 5 - Senado Federal - PEC 68/2005 442

Anexo 6 - Senado Federal - PEC 32/2007 452

Anexo 7 - Senado Federal - PEC 6/2008 464

Anexo 8 - Senado Federal - PEC 30/2008 475

Anexo 9 - Senado Federal - PEC 51/2009 486

Anexo 10 - Senado Federal - PEC 12/2010 501

Anexo 11 - Senado Federal - PEC 4/2011 531

Anexo 12 - Senado Federal - PEC 44/2012 543

Anexo 13 - Senado Federal - PEC 58/2012 552

Anexo 14 - Senado Federal - PEC 3/2013 571

Anexo 15 - Senado Federal - PEC 50/2013 586

Anexo 16 - Senado Federal - PEC 68/2013 596

Anexo 17 - Senado Federal - PEC 3/2014 612

Anexo 18 - Câmara dos Deputados - PEC 92/1995 620

Anexo 19 - Câmara dos Deputados - PEC 131/1995 677

Anexo 20 - Câmara dos Deputados - PEC 430/1996 735

Anexo 21 - Câmara dos Deputados - PEC 510/1997 840

Anexo 22 - Câmara dos Deputados - PEC 557/1997 1029

Anexo 23 - Câmara dos Deputados - PEC 620/1998 1060

Anexo 24 - Câmara dos Deputados - PEC 71/1999 1275

Anexo 25 - Câmara dos Deputados - PEC 473/2001 1425

Anexo 26 - Câmara dos Deputados - PEC 546/2002 1433 
Anexo 27 - Câmara dos Deputados - PEC 566/2002

Anexo 28 - Câmara dos Deputados - PEC 569/2002

Anexo 29 - Câmara dos Deputados - PEC 20/2003

Anexo 30 - Câmara dos Deputados - PEC 484/2005

Anexo 31 - Câmara dos Deputados - PEC 128/2007

Anexo 32 - Câmara dos Deputados - PEC 262/2008

Anexo 33 - Câmara dos Deputados - PEC 342/2009

Anexo 34 - Câmara dos Deputados - PEC 393/2009

Anexo 35 - Câmara dos Deputados - PEC 408/2009

1503

Anexo 36 - Câmara dos Deputados - PEC 434/2009

1516

Anexo 37 - Câmara dos Deputados - PEC 441/2009

Anexo 38 - Câmara dos Deputados - PEC 17/2011

Anexo 39 - Câmara dos Deputados - PEC 143/2012

1538

Anexo 40 - Câmara dos Deputados - PEC 161/2012

1546

Anexo 41 - Câmara dos Deputados - PEC 227/2012

1552

Anexo 42 - Câmara dos Deputados - PEC 238/2013

1559

Anexo 43 - Câmara dos Deputados - PEC 243/2013

1565

Anexo 44 - Câmara dos Deputados - PEC 275/2013

1571

Anexo 45 - Câmara dos Deputados - PEC 367/2013

1583

Anexo 46 - Câmara dos Deputados - PEC 378/2014

Anexo 47 - Senado Federal - Comissão de Constituição, Justiça e Cidadania - Arguição de Luís Roberto Barroso

Anexo 48 - Senado Federal - Comissão de Constituição, Justiça e Cidadania - Arguição de Teori Albino Zavascki

Anexo 49 - Senado Federal - Comissão de Constituição, Justiça e Cidadania - Arguição de Rosa Maria Weber Candiota da Rosa

Anexo 50 - Senado Federal - Comissão de Constituição, Justiça e Cidadania - Arguição de Luiz Fux

Anexo 51 - Senado Federal - Comissão de Constituição, Justiça e Cidadania - Arguição de José Antonio Dias Toffoli 
Anexo 52 - Senado Federal - Comissão de Constituição, Justiça e Cidadania - Arguição de Carlos Alberto Menezes Direito

Anexo 53 - Senado Federal - Comissão de Constituição, Justiça e Cidadania - Arguição de Cármen Lúcia Antunes Rocha

Anexo 54 - Senado Federal - Comissão de Constituição, Justiça e Cidadania - Arguição de Enrique Ricardo Lewandowski

Anexo 55 - Senado Federal - Comissão de Constituição, Justiça e Cidadania - Arguição de Eros Roberto Grau

Anexo 56 - Senado Federal - Comissão de Constituição, Justiça e Cidadania - Arguição de Joaquim Benedito Barbosa

Gomes

Anexo 57 - Senado Federal - Comissão de Constituição, Justiça e Cidadania - Arguição de Carlos Augusto Ayres de Freitas Britto

Anexo 58 - Senado Federal - Comissão de Constituição, Justiça e Cidadania - Arguição de Antonio Cezar Peluso

Anexo 59 - Senado Federal - Comissão de Constituição, Justiça e Cidadania - Arguição de Gilmar Ferreira Mendes

Anexo 60 - Senado Federal - Comissão de Constituição, Justiça e Cidadania - Arguição de Ellen Gracie Northfleet

Anexo 61 - Senado Federal - Comissão de Constituição, Justiça e Cidadania - Arguição de Nelson Azevedo Jobim

Anexo 62 - Senado Federal - Comissão de Constituição, Justiça e Cidadania - Arguição de Maurício José Corrêa

Anexo 63 - Senado Federal - Comissão de Constituição, Justiça e Cidadania - Arguição de José Francisco Rezek

Anexo 64 - Senado Federal - Comissão de Constituição, Justiça e Cidadania - Arguição de Ilmar Nascimento Galvão

Anexo 65 - Senado Federal - Comissão de Constituição, Justiça e Cidadania - Arguição de Marco Aurélio Mendes de Farias Mello

Anexo 66 - Senado Federal - Comissão de Constituição, Justiça e Cidadania - Arguição de Carlos Mário da Silva Velloso

Anexo 67 - Senado Federal - Comissão de Constituição, Justiça e Cidadania - Arguição de José Celso de Mello Filho 
Anexo 68 - Senado Federal - Comissão de Constituição, Justiça e Cidadania - Arguição de José Paulo Sepúlveda Pertence 2671

Anexo 69 - Senado Federal - Comissão de Constituição, Justiça e Cidadania - Arguição de Paulo Brossard de Souza Pinto

Anexo 70 - Senado Federal - Comissão de Constituição, Justiça e Cidadania - Arguição de Célio de Oliveira Borja

Anexo 71 - Senado Federal - Comissão de Constituição, Justiça e Cidadania - Arguição de Carlos Alberto Madeira

Anexo 72 - Assembleia Nacional Constituinte 1997/1998 - Quadro Histórico de sugestões relativas ao art. 101

Anexo 73 - Assembleia Nacional Constituinte 1997/1998 - Discussão e votação Destaque Nelson Jobim a Emenda que propõe criar o Supremo Tribunal Constitucional e discussão e votação Emenda Egidio Ferreira Lima

Anexo 74 - Assembleia Nacional Constituinte 1997/1998 - Discussão e votação de destaques e emendas sobre Tribunal Constitucional e STF

Anexo 75 - Assembleia Nacional Constituinte 1997/1998 - Emenda substitutiva Centrão

Anexo 76 - CONSTITUIÇÃO DA REPÚBLICA DOS ESTADOS UNIDOS

DO BRASIL - 24 de fevereiro de 1891

Anexo 77 - CONSTITUIÇÃO DA REPÚBLICA DOS ESTADOS UNIDOS

DO BRASIL - 16 de julho de 1934

2843

Anexo 78 - CONSTITUIÇÃO DA REPÚBLICA DOS ESTADOS UNIDOS

DO BRASIL - 10 de novembro de 1937

Anexo 79 - CONSTITUIÇÃO DA REPÚBLICA DOS ESTADOS UNIDOS

DO BRASIL - 18 de setembro de 1946

2851

Anexo 80 - CONSTITUIÇÃO DA REPÚBLICA FEDERATIVA DO BRASIL

- 24 de janeiro de 1967

2855

Anexo 81 - CONSTITUIÇÃO DA REPÚBLICA FEDERATIVA DO BRASIL

-5 de outubro de 1988

2865

Anexo 82 - Discurso para a posse do Presidente do STF - 10 de setembro 
Anexo 83 - Senado Federal - Quadro Comparativo das Constituições de 1946, 1967, Emenda Constitucional no 1 de 1969 e Constituição de 1988

Anexo 84 - Senado Federal - Regimentos Internos do Senado Federal -

Regência no tempo quanto à aprovação dos ministros do STF, sempre por votação secreta, com menção anterior a sessão secreta, que se torna pública apenas a partir de 1989 2885

Anexo 85 - Senado Federal - Regimentos Internos do Senado Federal RISF 1959 - atualizado até 1968 1-2

Anexo 86 - Senado Federal - Regimentos Internos do Senado Federal RISF 1959 - atualizado até 1968 2-2

Anexo 87 - Senado Federal - Regimentos Internos do Senado Federal RISF 1970 - atualizado até 1994

Anexo 88 - Senado Federal - Regimentos Internos do Senado Federal RISF 1970 - atualizado até 1998

Anexo 89 - Senado Federal - Regimentos Internos do Senado Federal RISF 1971 - atualizado até 1971

Anexo 90 - Senado Federal - Regimentos Internos do Senado Federal RISF 1989 - atualizado até 1989 - Texto editado em conformidade com a Resolução № 18 de 18-04-1989 que produziu a adequação do Regimento à Carta 88. 


\section{Lista de tabelas}

Tabela 1 - Classificação das alterações propostas

Tabela 2 - Tabela 2 - Indicações sem sucesso de candidatos a juízes das Supremas Cortes do Brasil e dos EUA

Tabela 3 - Dados relativos aos 25 ministros nomeados para o STF entre 1985 e 2014 (presidente, datas, nascimento, idade e período de exercício)

Tabela 4 - Dados relativos aos 25 ministros nomeados para o STF entre 1985 e 2014 (faculdade, carreira anterior, Estado de atuação profissional, escolaridade, quórum de aprovação no Senado)

Tabela 5 - Quantidade de ministros nomeados por cada presidente da República, entre 1985 e 2014 


\section{Lista de quadros}

Quadro 1 - Comparativo das Supremas Cortes

Quadro 2 - Comparativo das Cortes Constitucionais

Quadro 3 - Propostas de Emenda à Constituição com origem no Senado Federal

Quadro 4 - Propostas de Emenda à Constituição com origem na Câmara dos Deputados

Quadro 5 - As cinco únicas recusas pelo Senado de indicados para o STF

Quadro 6 - As 36 indicações sem sucesso de para a Suprema Corte dos EUA 243

Quadro 7 - Quadro 7 - Votação nas aprovações de ministros do STF na CCJ 320

Quadro 8 - Relações e escolha entre ministros e presidentes da República 323 


\section{Abreviaturas}

ABA - American Bar Association

ADI - Ação Direta de Inconstitucionalidade

AEUDF - Associação de Ensino Unificado do Distrito Federal

AGU - Advocacia Geral da União

AMB - Associação dos Magistrados Brasileiros

CCJ - Comissão de Constituição e Justiça do Senado Federal

CCJC - Comissão de Constituição, Justiça e Cidadania do Senado Federal

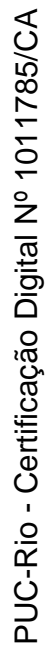

CD - Câmara dos Deputados

CF - Constituição Federal

CNJ - Conselho Nacional de Justiça

CONAMP - Associação Nacional do Membros do Ministério Público

CPC - Código de Processo Civil

CRFB - Constituição da República Federativa do Brasil

DL - Decreto-lei

EUA - Estados Unidos da América

FGV - Fundação Getúlio Vargas

FMU - Centro Universitário das Faculdades Metropolitanas Unidas

$\mathrm{L}-$ Lei

MC - Medida Cautelar

MS - Mandado de Segurança 
MP - Medida Provisória

MP - Ministério Público

MPT - Ministério Público do Trabalho

OAB - Ordem dos Advogados do Brasil

PDT - Partido Democrático Trabalhista

PEC - Proposta de Emenda à Constituição

PMDB - Partido do Movimento Democrático Brasileiro

PRN - Partido da Reconstrução Nacional

PSDB - Partido da Social Democracia Brasileira

PT - Partido dos Trabalhadores

PUC/MG - Pontifícia Universidade Católica de Minas Gerais

PUC-Rio - Pontifícia Universidade Católica do Rio de Janeiro

PUC/SP - Pontifícia Universidade Católica de São Paulo

RISF - Regimento Interno do Senado Federal

SF - Senado Federal

STF - Supremo Tribunal Federal

STJ - Superior Tribunal de Justiça

TJSP - Tribunal de Justiça de São Paulo

TRF - Tribunal Regional Federal

TRT - Tribunal Regional do Trabalho

TST - Tribunal Superior do Trabalho

UEG - Universidade do Estado da Guanabara

UERJ - Universidade do Estado do Rio de Janeiro 
UFAC - Universidade Federal do Acre

UFMG - Universidade Federal de Minas Gerais

UFRGS - Universidade Federal do Rio Grande do Sul

UFRJ - Universidade Federal do Rio de Janeiro

UFSC - Universidade Federal de Santa Catarina

UFSE - Universidade Federal de Sergipe

UFSM - Universidade Federal de Santa Maria

UNB - Universidade de Brasília

UNICAMP - Universidade Estadual de Campinas

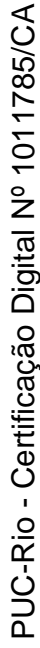

UNICEUB - Centro Universitário de Brasília

UNISINOS - Universidade do Vale do Rio dos Sinos

USP - Universidade de São Paulo 
"Nas nações ibéricas, à falta dessa racionalidade da vida, que tão cedo experimentaram algumas terras protestantes, o princípio unificador foi sempre representado pelos governos."

Sérgio Buarque de Holanda Raízes do Brasil 